\title{
Analysis of Environmental Complexities and the Associated Dynamics for Development of SME Sector in Pakistan
}

\author{
*Abdul Majid ${ }^{1}$, Muhammad Yasir¹, Naila Tabassum² \\ ${ }^{1}$ University of Sheffield, United Kingdom \\ 2Jinnah College for Women, University of Peshawar, Pakistan \\ *a.majid@sheffield.ac.uk
}

\begin{abstract}
The primary objective of this research is to explore the complex and dynamic behavior of the business environment for small and medium enterprises. While investigating into the complexities and dynamism of the business environment, this research would also attempt to suggest some guidelines for the development and growth of SME sector in Pakistan. Cluster sampling technique has been used for this research. For the purpose of data collection semi structured interviews have be conducted from eighty entrepreneurs from four SME clusters. This research work concludes that the business environment in Pakistan is relatively more complex in nature than other developing countries. To develop the SME sector in Pakistan it is necessary to understand and manage the environmental complexities with in-depth environmental analysis.
\end{abstract}

Key Words: Environment, Complexity, SME, Pakistan

\section{Introduction}

Negative effects of environmental complexities and dynamism on business organizations has long been a major area of investigation for many researchers and theorists. In particular, since the seminal work of Emery \& Trist (1965) and its followers from Thomson (1967), Duncan (1972) to Post Modern researchers as if Anderson (1999) and Boyne \& Meier (2009) it has been well documented that environmental complexities and dynamism create an unfavorable environment for business development. The study of the Dess \& Deard (1984) was one of the pioneering studies on the concepts of dynamism and complexities, which synthesized the already existing models and frameworks by intellectually defining the dimensions of task environment. In spite of the growing literature on the dynamics of organizational environment, there are still two fundamental areas that deserve in-depth studies. First, the complexities and behavior of the organizational environment of developing countries like Pakistan are still under explored as most of the research outcomes, available literature, units of analysis, and conceptual models are related with the context of the developed nations. The same arguments are available in the studies of Farjoun (2007). Second, as noted by Elmaraghy (2011), that most of the research studies whether it is conducted in developed countries or in the developing context concentrated on large-scale businesses and manufacturing units. Very marginal studies are available where researchers especially focus on the effects of dynamism and complexity of the business environment on small and medium enterprises. Small and medium enterprises are one of the major contributors in the economy of Pakistan in terms of its exports, employment and gross domestic products. SME sector in Pakistan is currently facing drastic situation due to number of environmental complexities. This context dependent study initially analyzes the environment of Pakistan to clearly understand its complex and dynamic situation, then would focused on the environment of SME sector to clearly outline the state of complex environment that are currently facing by the small and medium enterprises. This research would not only study the behavior of environmental variables, but also focused to improve our understanding about the rate of changes in environmental variables, absence of pattern and unpredictability of the business environment for small and medium enterprises in Pakistan. Lastly, this study would attempt to suggest guidelines that would hopefully help the entrepreneurs in Pakistan to analyze the business environment and develop their enterprises up to the maximum potential.

Complexity and Dynamism: Complexity and the complex system are two important variables that have been discussed heavily by the organizational researchers during the last fifty years. In the available literature, the main purpose of analyzing the complexity as well as complex system is to develop better understanding of the organizational environment. The preliminary researchers in the field of complexity include Emery \& Trist (1965), Thomson (1967) and Duncan (1972). Their early contributions added considerably in the field of contingency theory (Osborn \& Hunt, 1974). Complexity can be defined as the 
number of factors and heterogeneity amongst these factors in environment (Duncan, 1972). In complex system, each part is interconnected with the other part (Cunha, Miguel \& Rego, 2010). Dess and Beard (1984) associated complexity with the number, diversity and interrelationship of variables. In the available literature, researchers have classified complexity in various ways e.g. internal complexity and external complexity (Duncan, 1972), vertical, horizontal and spatial (Daft, 1992), unintentional complexity (Ashkenas, 2007) and allot of other complexities like technical complexities, operational complexities etc. There is one confusing and interchangeable term in organizational literature for complex system is complicated system. Most of the practitioners interchange these two concepts and considered complication and complexity as a same thing. Cilliers (1998) who is one of the postmodern organizational researchers in the field of complexity remarkably differentiated between complex and complicated systems. Cilliers (1998) differentiated complex system and complicated system in the following words: "Important distinction and one that is equally difficult to maintain consistently, is the one between complex and complicated. Some systems have a very large number of components and perform sophisticated tasks, but in a way that can be analysed (in the full sense of the word) accurately. Such a system is complicated. Other systems are constituted by such intricate sets of non-linear relationships and feedback loops that only certain aspects of them can be analysed at a time. Moreover, these analyses would always cause distortions. Systems of this kind are complex. I have heard it said (by someone from France, of course) that a jumbo jet is complicated, but that a mayonnaise is complex (P. 3)".

Cilliers (1998) also described ten characteristics of complex system. These characteristics include:

- Complex system consists of large number of elements. If the elements are small in number then the behaviour of elements of system is complex in nature;

- Elements of the complex systems must interact with each other. The interaction should be dynamic;

- The numbers of interactions of the elements of a complex system are not equal. Some elements are more active in interaction while others are less;

- The interaction of the elements should be non-linear. It means that output would not directly proportion to the input;

- The interaction usually have a short range i.e. interactions usually take place with the immediate neighbours;

- The effect of the interaction of any element may eventually reflect back on itself, sometimes directly and sometimes indirectly. The feedback can be positive or negative;

- Complex systems are usually open systems and difficult to define its boundaries;

- Complex system is not in equilibrium state;

- Complex systems have a history. Its past behaviours are also responsible for its current behaviours and interactions;

- Each element of the complex system has imperfect information about the behaviour of the whole system, it responds only to information that is available locally.

On the other hand, dynamism according to Dess \& Beard (1984) refers to the rate of change, absence of pattern and unpredictability of the environment. These unpredictable changes create uncertainties for the organization. They viewed these complexities to be characterized with heterogeneity and the range of organizational activities within the organizational environment. Dess and Beard also contend that highly complex environment generates greater uncertainty for the managers than lesser complex environment. While explaining the environmental complexity, Dess and Beard presented it as a dimension of task environment, but most of the earlier researchers like Child (1972) and Duncan (1972) consider complexity as a characteristic of organizational environment. The relationship between environmental complexity and dynamism with business performance is negative, as elaborated by Fariborz (1996), who states that; "the more complex and dynamic environment, the higher is the level of business failure (p. 696)." In complexity theory, the negative relationship of complexity with organizational performance and its positive relationship with business failure and negative growth are supported by a wide range of research studies including Fernandez (2005) and Heinrich \& Fournier (2004). This research is specifically analyzes the business environment of SME sector, therefore it is necessary to understand the basic notion of small and medium enterprises. The huge problem in this regard is the fundamental definition of small and medium enterprises. Every country has adopted its own created definition of SME e.g. any organization with less than 100 employees is considered as SME in Australia, Indonesia, Thailand and China (Witoon, 1999). In USA, any organization having less than 500 employees, and in Japan with less than 200 employees with total assets up to 100 million dollars is considered as small and medium enterprises (Hall, 2002). Any firm that is indexed in Russel Indices (Russel 2500 and Russel Midcap) is 
also considered as SME in United States. In European Union, any firm that have 50 to 250 employees with annual turnover between 7 to 40 million Euros having total assets less than 27 million Euros and which more than 75 percent ownership is in the hand of small corporation is considered as SME.

In Pakistan, various entities have adopted their own definitions of SME. According to Small and Medium Enterprises Development Authority any organization with paid up capital of 25 million rupees and less than 250 employees are considered as SME (SMEDA, 2007), while SME bank categorized the organization with respect to their total assets. According to SME bank, any organization with less than 20 million of total assets is considered as SME. State Bank of Pakistan in its prudential regulation (2011) of small and medium enterprises defined SME in the following word "an entity, ideally not a public limited company, which does not employ more than 250 persons (if it is manufacturing /service concern) and 50 persons (if it is trading concern) and also fulfils the following criteria of either ' $a$ ' and ' $c$ ' or ' $b$ ' and ' $c$ ' as relevant:

- A trading/service concern with total assets at cost excluding land and building up to Rs 50 million.

- A manufacturing concern with total assets at cost excluding land and building up to Rs 100 million.

- Any concern (trading, service or manufacturing) with net sales not exceeding Rs 300 million as per latest financial statements.

An Individual, if he or she meets the above criteria, can also be categorized as an SME (p. 05)".

\section{Analysis of the Research Context}

Pakistan is a developing country. Economy of Pakistan consists of three major sectors i.e. the agriculture, the industry, and the services (Ministry of Finance, 2012). Agriculture and industrial sectors are jointly called the commodity-producing sector (CPS). The economy of Pakistan, at present, is facing a number of challenges that have the potential to adversely affect its performance. The fiscal year 2011-12 has witnessed a continuous downfall in most of the economic indicators (Pakistan Bureau of Statistics, 2012). There are four major challenges that economy of Pakistan is currently facing, these are political instability, war against terrorism, energy crisis and unfavorable law and order situation. The economy had to suffer heavy losses due to these challenges during FY 2011-12. In this period, the real GDP growth rate was recorded at 3.7 percent, which is the one of the lowest figure since 1992-93. The growth rate in manufacturing sector was around 3.0 percent as compared to the 20 percent during the financial year 2004-05. The negative growth has also been recorded in its exports while total import items increased by 15 percent. The official inflation rate during 2011-12 was 12 percent while it is more than 20 percent according to nongovernmental statistics. Similar situation has been observed in all the stock exchanges of Pakistan including Karachi Stock Exchange, Lahore Stock Exchange, and Islamabad Stock Exchange. As far as SME sector is concerned, about 99 percent of business organizations in Pakistan can be considered as small and medium enterprises in which 53 percent are operating in trade, 20 percent are manufacturing, 22 percent are services and 5 percent are other SMEs (SMEDA, 2007). In the last financial year i.e. 2011-12 the marginal growth of 5.0 percent has been recorded in this sector.

\section{Methodology}

This research is a unique opportunity to examine the complexities and dynamism of the business environment related with SME sector. Besides, this research would also attempt to provide procedures and guidelines for entrepreneurs to understand the changes taking place in the business environment of Pakistan, that would hopefully help them to keep align their small as well as medium enterprises with environmental changes and concentrate on the achievements of targets for sustainable business development. Cluster sampling technique has been used for this research. Data was collected through semi-structured interviews from eighty entrepreneurs from four SME clusters included: Fan manufacturing cluster Gujranwala (20); Light engineering cluster Gujranwala (20); Cotton ginning cluster Bahawalpur and Multan (20) and Electrical fitting industrial cluster Sargodha (20). Each of the four selected SME clusters were independent, non-diversified and less than 100 employees. The de jure sample was 80 while de facto sample was 73 . These four SME clusters are the selected based on their proper organizational structure, contribution in economy as well as providing the employment opportunities. Development of SME sector in Pakistan is taken as dependent variable with two independent variables: environmental complexities and dynamism. Initially the pilot study was conducted, and content analysis technique was used for the identification of variables from the collected data. Pilot study was conducted on eight entrepreneurs of eight firms from four different clusters that were not included in the final 
sample. After identification of external variables, further data was collected on the selected variables through semi-structured interviews.

\section{Results and Discussion}

SME is a major sector that has a potential to contribute heavily in the development of Pakistan. In the current scenario when the survival is a major issue for most of the production units, it is still a question mark on the future of small and medium enterprises in Pakistan. After analyzing the data from four SME clusters various complex variables have been identified. The percentage of responses against each complex variable is presented in the table below. In the table-1, variables are arranged in descending order with respect to percentage of responses.

Table 1: Complex Environmental Variables

\begin{tabular}{|c|c|c|}
\hline Complexities & $\begin{array}{ll}\text { In } & \text { favor } \\
\% & \\
\end{array}$ & $\begin{array}{l}\text { Against } \\
\%\end{array}$ \\
\hline Energy Crisis & 100 & 0 \\
\hline Terrorism & 100 & 0 \\
\hline Lack of Finances \& High Interest Rates & 100 & 0 \\
\hline lack of Government Support & 100 & 0 \\
\hline Lack of Modern Technology & 70 & 30 \\
\hline Lack of research and development & 70 & 30 \\
\hline Lack of collaboration & 50 & 50 \\
\hline Marketing of SME products & 45 & 55 \\
\hline Shortage of skilled labor & 40 & 60 \\
\hline
\end{tabular}

The above table reveals that there are nine major environmental variables that negatively affect the SME sector in Pakistan. There are many other variables that also have adverse effects on the development of SME sector, but adopting the parsimonious approach the scope of this research is limited to the abovementioned nine variables. In the following paragraphs, we will discuss each variable one by one. Energy crisis is currently a major reason behind the fall of SME sector in Pakistan. Currently Pakistan is facing a shortfall of 6000MW per day of electricity. Due to this huge shortfall, most of the production units remain nonoperational for average 17-18 hours per day. The major problem for small and medium enterprises is that they cannot afford the alternate sources of energy like power generators or LPG etc. therefore there output is continuously decreasing since last five years. Terrorism is one of the other major reasons behind the continuous decline of the SME sector in Pakistan. The easy targets for terrorists are small enterprises, retail markets, and community centers because of the lack of facilities available for the security purposes. Therefore, due to terrorist activities the small and medium enterprises suffered huge lose (financial as well as nonfinancial) during the last ten years. The terrorist attacks not only destroys the business community but also damaged the infrastructures facilities in a specific regions. The terrorism is also one of the major reasons that foreign donor agencies and private equity partners are reluctant to invest in Pakistan and their contributions are continuously decreasing since last many years. Shortage of financial resources is another major problem for SME sector in Pakistan. Equity financing is the major source of finance in most of the small and medium enterprises. The financial institutions ask for huge collateral against the loans, therefore it is the major reason that 70 percent of the SME finances comes from equity financing. On the other hand the interest rate charged by various financial institutions is very high i.e. 12 percent. These financial complexities create very drastic situations for SME development. In that prevailing situation, Government of Pakistan remained ineffective in the development of any policy for the development of SME sector. In the last decade, Government of Pakistan paid its full attentions to handle other strategic non-developmental issues like terrorism, law and order, corruption, nepotism and judiciary etc. Therefore, all the respondents of the survey have similar opinion that government did not help the SME sector to resolve its problem. 
Another most important issue for the SME sector development is the lack of research and development activities. As we discussed earlier that SME sector is facing the immense shortfall of financial resources and in that situation, it is impossible for the small enterprises to allocate the funds for research and development. The lack of research activities is also a major reason that most of the enterprises are using old and outdated machinery for their production purposes. Seventy percent of the respondents responded that their production machinery is more than 15 to 20 years old. About seventy percent of the respondents are in the favor of the argument that that there is no research activities in SME sector and they are unaware about the latest development in their respective fields. In the current global scenario, the world is moving toward collaboration instead of competition. All the major businesses in the world have adopted various types of collaboration by minimizing the competition in international market. In SME sector of Pakistan, most of the enterprises are working individually. There is marginal evidence that small and medium enterprises have made any type of consortiums or virtual organization to exploit temporary market opportunities or to cope with the current market conditions. Fifty percent respondents responded that there is no collaboration between the enterprises. In some SME clusters e.g. garments etc. there is some evidence of coordination that some organization made a consortium to collaborate with each other and capture the market demand. But one or two cases in whole of the economy have no effect on the whole sector or even specific cluster development. Another major problem for SME sector is the absence of the marketing activities. The small and medium enterprises in Pakistan do not market their products properly in local as well as in international market. Therefore, the local and international buyers have little information about the products of SME sector in Pakistan. That would be the major reason that the graph of annual sale of SME sector is continuously decreasing. In Pakistan, there are very few institutions that are providing training to the workforce of SME sector in Pakistan. These institutions include Pakistan Institute of Management Sciences (PIMS), Technical Training and Vocational Authority (TEVTA), Provincial Vocational Training Councils, Skill Development Council etc. These institutions initiated various programs for human resource development, but their contributions in SME sector are heavily questionable. Forty percent of the respondents have the opinion that there is shortage of skilled labor force in SME sector while sixty percent of the respondents are against them. Most of the workers are trained through on the job training process.

To cope with the current situation, it is necessary to manage all these environmental complexities holistically. All the stakeholders including government of Pakistan play their role to minimize the effects of these variables. To develop the SME sector it, is necessary to provide the continuous energy for manufacturing purposes. Government of Pakistan should facilitate the SME sector by exploring the alternate sources of energy like coal, wind, and solar energy etc. Pakistan has huge resources of coal, especially in Thar. It is expected that the proposed Thar project would generate $1000 \mathrm{MW}$ electricity per year. On the other hand, wind energy if exploited only in the coastal areas of Sindh and Baluchistan has the potential to generate about $50000 \mathrm{MW}$ of electricity per year. Pakistan can also benefit from the solar energy, which is a huge and non-delectable source of energy (Alternate Energy Development Board, 2010). These potential sources of energy have not so far been utilized. To resolve the energy crisis in the country, the Government of Pakistan may start the projects sooner to exploit these energy reserves. Beside the arrangements of alternate sources of energy, the Government of Pakistan may decrease the electricity and gas tariffs to facilitate the SME sector. As far as terrorism is concerned, it is beyond the capacities or direct domain of SME sector to control it. Therefore, the Government of Pakistan may develop a comprehensive policy on terrorism with the help of international partners to control and minimize its effects on the economy of Pakistan. To solve the financial problems and deal with the high interest rates, financial institution should provide loans to SME sector with reasonable collateral on subsidized interest rates and Government of Pakistan should play its role in this regard. Besides all these, there is a strong need to enhance the research and development activities in various dimensions of SME sector like production, marketing and human resource development. It will not only identify the weak areas but also suggest guidelines to make improvements accordingly.

\section{Conclusion}

Business environment in Pakistan is complex in nature. The basic characteristics of its environment include larger number of variables with unpredictable changes. The unique behavior of the Pakistani environment is the unpredictable behavior of the variables comprising the business environment that create drastic situation for the manager to make appropriate decisions. This research work has attempted to identify the complex variables that affect most of the enterprises in SME sector of Pakistan. The intensity of these variables is high enough that survival is a major challenge for most of the small and 
medium enterprises. In the current scenario when most of the entrepreneurs are incapable (due to the lack of education, proper training as well as deficiency of financial resources) to understand the intensity of variables change this study would hopefully help them to understand their business environment. But just understanding is not enough to cope with the current situation. SME sector requires a broad base and long-term policy for its survival and development and the role of the Government of Pakistan is very important in this regard. All the players (including entrepreneurs, government of Pakistan, financial institutions and regulatory agencies) of SME sector have to develop a holistic policy, in which each player is not only responsible for his job but also cooperate with other players to achieve the desired results. Without doing this, it would be practically impossible for SME sector to survive and long term growth.

\section{References}

Alternative Energy Development Board. (2012). Alternate sources of energy. Retrieved from www.aedb.org/ as on February 11, 2010,

Anderson, P. (1999). Complexity theory and organization science. Organization Science, 10(3), 216-232.

Ashkenas, R. (2007). Simplicity-based management. Harvard Business Review, 3, 101-109.

Boyne, G. A. \& Meier, K. J. (2009). Environmental turbulence, organizational stability, and public service performance. Administration \& Society, 40(8), 799-824.

Child, J. (1972). Organizational structure, environment and performance: The role of strategic choice. Sociology: The Journal of the British Sociological Association, 6(1), 1-22.

Cilliers, P. (1998). Complexity and Postmodernism: Understanding Complex Systems, Routledge, London.

Cunha, G., Miguel, P. E. \& Rego, A. (2010). Complexity simplicity simplexity. European Management Journal, 28(2), 85-94.

Daft, R. L. (1992). Organization theory and design (4th. Ed.). St Paul, MN: West Publishing.

Dess, G. \& Beard, D. (1984). Dimensions of organizational task environments. Administrative Science Quarterly, 29, 52-73.

Duncan, R. B. (1972). Characteristics of organizational environments and perceived environmental Uncertainty. Administrative Science Quarterly, 17, 313-327.

ElMaraghy, H. A. (2011). Enabling Manufacturing Competitiveness and Economic Sustainability. Montreal, Springer.

Emery, F. E. \& Trist, E. L. (1965). The causal texture of organizational environments. Human Relations, 18, 21-31.

Fariborz, D. (1996). Organizational complexity and innovation: Developing and testing multiple contingency models. Management Science, 42(5), 693-716.

Farjoun, M. (2007). The end of strategy? Strategic Organization, 5(3), 197-210.

Fernandez, S. (2005). Developing and testing an integrative framework of public sector leadership: Evidence from the public education arena. Journal of Public Administration Research and Theory, 15, 197-217.

Hall, C. (2002). Profile of SMEs and SME Issues in East Asia. In Charles, H. \& Boon-Chye, L. (Eds), the Role of SMEs in National Economies in East Asia. Cheltenham: Edward Elgar.

Heinrich, C. \& Fournier, E. (2004). Dimensions of publicans and performance in substance abuse treatment organizations. Journal of Policy Analysis and Management, 23, 49-70.

Ministry of Finance, Government of Pakistan. (2012). Economic survey of Pakistan 2011-2012. Retrieved from, http://www.finance.gov.pk/survey_1112.html as on July 10, 2012.

Osborn, R. N. \& Hunt, J. G. (1974). Environment and organizational effectiveness. Administrative Science Quarterly, 19(2), 231-246.

Pakistan Bureau of Statistics. (2012). National Accounts. Retrieved from http://www.pbs.gov.pk/content/detail-tables-1 as on June 12, 2012 as on August 12, 2011.

Small and Medium Enterprises Development Authority. (2007). SME Policy 2007. Retrieved from, http://www.smeda.org.pk/downloads/smepolicy2007.pdf as on March 22, 2012.

State Bank of Pakistan. (2012). Prudential Regulations for Small and Medium Enterprises Financing. Retrieved from http://www.sbp.org.pk/ publications/ prudential/PRs-SMEs.pdf as on June 12, 2012.

Thomson, J. D. (1967). Organizations in action. New York: McGraw-Hill.

Witoon, S. (1999). SMEs the Main Pillar of Industry (in Thai), Bangkok: Technology Promotion Association (Thailand-Japan). 